\title{
Electrooxidation of $\mathrm{C}_{4}$ Polyols on Platinum Single-Crystals: $\mathrm{A}$ Computational and Electrochemical Study
}

\author{
Gabriela Soffiati, José L. Bott-Neto, Victor Y. Yukuhiro, Cléo T. G. V. M. T. Pires, Carlos C. Lima, \\ Cinthia R. Zanata, Yuvraj Y. Birdja, Marc T. M. Koper, Miguel A. San-Miguel, and Pablo S. Fernández*
}

Cite This: J. Phys. Chem. C 2020, 124, 14745-14751

Read Online

ACCESS 1

Llll Metrics \& More

Article Recommendations

Supporting Information

ABSTRACT: Many polyols are abundant and cheap molecules highly spread in the biomass. These molecules have an enormous potential to be used in electrochemical devices to generate energy and/or value-added molecules. The electrooxidation of polyols can produce different substances of interest in the chemical industry concomitantly to high purity hydrogen in electrolyzers. The cost in the production of all these chemicals depends, among other factors, on the develop of more active and selective catalysts. However, in order to search for these materials using computational experiments, it is mandatory to have a better understanding of the fundamental aspect of the reactions, which permit to base the search on the adsorption energies of one or more key reaction intermediates. To contribute to this task, we performed (spectro)-

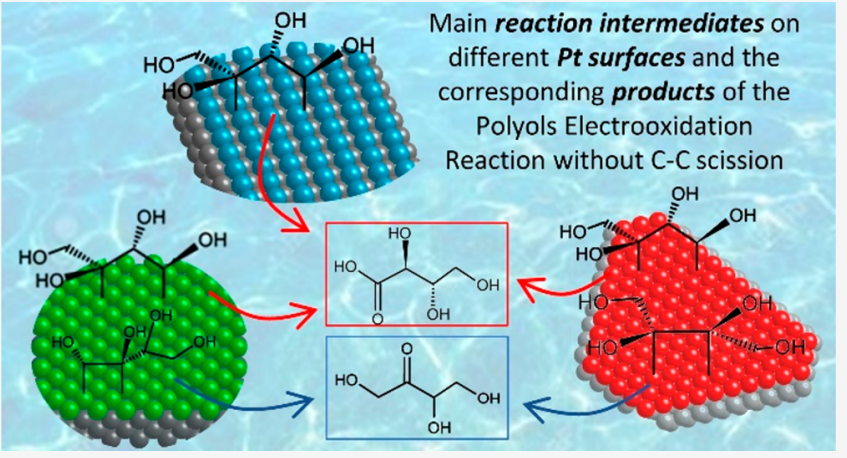
electrochemical and computational experiments to study the electrooxidation of $\mathrm{C}_{4}$ polyols. We show that the electrooxidation of polyols does not depend on the relative orientation of their $\mathrm{OH}$ groups. Besides, using Pt single crystals, we demonstrate that the trend for the oxidation of the primary carbon (relative to the secondary) increases in the order $\operatorname{Pt}(111)<\mathrm{Pt}(100)<\mathrm{Pt}(110)$ and that this result can be extended to polyols with longer carbon chains. Finally, computational experiments permit us to rationalize these trends looking at the relative stability of double dehydrogenated intermediates on the Pt basal planes.

\section{INTRODUCTION}

Increasing concerns about climate change and pollution are pushing the chemical industry to adopt greener strategies in their industrial processes. This scenario is creating significant opportunities for biobased economies. ${ }^{1}$ Hence, several biofuels are attractive candidates to be used in fuel cells (to produce energy and value-added compounds) and in electrolyzers (to produce value added products). ${ }^{2-6}$

In this context, the electrooxidation of polyols (EOP) has been studied extensively on platinum electrodes in acid media. These reactions share several similarities, irrespective of the exact molecule: (1) If the reaction occurs mainly without $\mathrm{C}-\mathrm{C}$ bond breaking, it is selective to the oxidation of the primary carbon, producing a highly reactive aldehyde that easily reacts to form the corresponding acid. ${ }^{7-11}$ (2) If the $\mathrm{C}-\mathrm{C}$ bond breaks, adsorbed $\mathrm{CO}$ is formed, which poisons the electrode. $^{12-18}$ (3) $\mathrm{CO}$ is not the only adsorbed reaction intermediate; there exist other species that strongly adsorb on the electrode, though their exact nature has remained elusive. ${ }^{19}$

Glycerol $(\mathrm{GlOH})$ is the most studied molecule for the EOP as it is the simplest structure containing a primary and a secondary carbon. Garcia et al. ${ }^{19}$ gave atomic-level insight about the selectivity of $\mathrm{GlOH}$ oxidation on $\mathrm{Pt}(111)$ and $\mathrm{Pt}(100)$ single crystal electrodes in terms of the oxidation of the primary or secondary alcohol. They found different selectivity on the two surfaces: only primary alcohol oxidation on $\mathrm{Pt}(100)$ and both primary and secondary alcohol oxidation on $\mathrm{Pt}(111)$. They related this selectivity difference to the different binding modes of the $\mathrm{GlOH}$ intermediate on the two surfaces.

In order to understand whether this selectivity pattern can be extended to longer polyols, we study here the electrooxidation of the $\mathrm{C}_{4}$ polyols. Polyols with four carbons (Figure 1) are the simplest polyols containing primary and secondary carbons as well as a pair of diastereomers, allowing to investigate the effect of the spatial orientation of the $\mathrm{OH}$ groups on the electrooxidation reaction.

The $\mathrm{C}_{4}$ polyols may serve as model molecules to understand the electrochemical behavior of important biomass feedstocks with longer carbon chains such as sorbitol, ribitol, xylitol and the corresponding acids and aldehydes.

Received: June 3, 2020

Revised: June 12, 2020

Published: June 16, 2020 


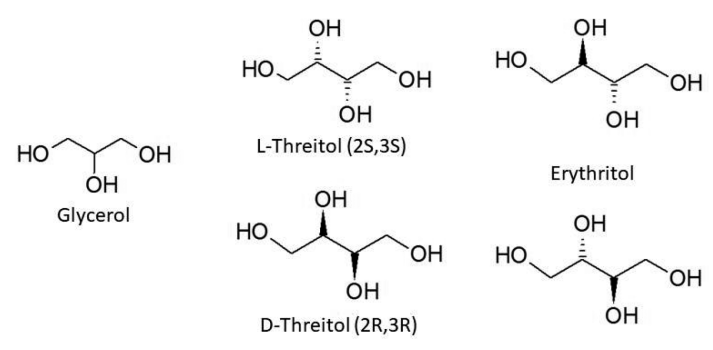

Figure 1. Structural comparison of the $\mathrm{C}_{4}$ polyols. The molecular structure of $\mathrm{GlOH}$ does not permit the existence of isomers. Threitol has two enantiomers (which are diasteromers of erythritol). Erythritol and its mirror image are the same molecule.

In this paper, we study the electrochemical oxidation of the $\mathrm{C}_{4}$ polyols on $\mathrm{Pt}(111), \mathrm{Pt}(100)$ and $\mathrm{Pt}(110)$ electrodes and the stability of the double-dehydrogenated $\mathrm{C}_{4}$ intermediates on $\mathrm{Pt}(111), \mathrm{Pt}(100)$ and $\mathrm{Pt}(110)$ using voltammetry, in situ infrared spectroscopy, and first-principles density functional theory (DFT) calculations.

The experiments show that while $\mathrm{Pt}(110)$ selectively oxidizes the primary carbon, $\mathrm{Pt}(111)$ and $\mathrm{Pt}(100)$ produce both the acid (oxidation of the primary carbon) and the ketone (oxidation of the secondary carbon), with the ratio ketone/ acid being higher for $\mathrm{Pt}(111)$.

The DFT calculations suggest that the production of the ketone is related to the ability of the surface to stabilize an enediol intermediate. Finally, erythritol and threitol show exactly the same oxidization characteristics, permitting us to conclude that the reaction is not sensitive to the $\mathrm{OH}$ group orientation.

\section{EXPERIMENTAL SECTION}

Electrochemical System and Surface Preparation. All electrochemical measurements were performed at room temperature $\left(25 \pm 1{ }^{\circ} \mathrm{C}\right)$ in a conventional three-electrode cell. A platinum foil and a reversible hydrogen electrode were used as counter and reference electrode, respectively. All potentials were measured versus a reversible hydrogen electrode (RHE) in contact with the blank electrolyte. The working electrodes were $\operatorname{Pt}(111), \operatorname{Pt}(110)$, and $\operatorname{Pt}(100)$ acquired from Icryst. Before each experiment, the electrodes were flame annealed and cooled in an $\mathrm{H}_{2}+\mathrm{Ar}$ atmosphere. Subsequently, the electrode was transferred to an electrochemical cell with the surface protected by a droplet of ultrapure water saturated with the $\mathrm{Ar} / \mathrm{H}_{2}$ mixture, thus avoiding contamination and reconstruction of the surface during its transfer to the electrochemical cell. ${ }^{20,21}$

In order to verify the ordering of the electrode surface, cyclic voltammograms were acquired between 0.05 and $0.80 \mathrm{~V}$ in $\mathrm{N}_{2}$ saturated $0.1 \mathrm{~mol} \mathrm{~L}^{-1} \mathrm{HClO}_{4}$ solution at $50 \mathrm{mV} \mathrm{s}^{-1}$. Next, the electrode was transferred to another cell containing $5 \mathrm{mmol}$ $\mathrm{L}^{-1}$ polyol (erythritol or D-threitol) in $0.1 \mathrm{~mol} \mathrm{~L}^{-1} \mathrm{HClO}_{4}$ solution. The linear positive potential sweep were obtained from 0.05 to $0.9 \mathrm{~V}$ at $1 \mathrm{mV} \mathrm{s}^{-1}$. The D-threitol was used because the racemic mixture, also commercially available, has lower purity.

In Situ FTIR. Spectra were acquired using a Shimadzu IR Prestige-21 equipped with a mercury-cadmium telluride (MCT) detector. A homemade spectroelectrochemical cell, with a $\mathrm{CaF}_{2}$ window, was attached to a specular reflection accessory (Veemax II, Pike Technologies). Before each experiment, the electrodes were prepared as described in the previous section. All spectra were recorded with an average of 256 interferograms and $4 \mathrm{~cm}^{-1}$ resolution during chronoamperometry experiments at potentials between 0.1 and $0.7 \mathrm{~V}$. The electrolyte was a $\mathrm{N}_{2}$-saturated $0.1 \mathrm{~mol} \mathrm{~L}^{-1} \mathrm{HClO}_{4}$ solution containing $5 \mathrm{mmol} \mathrm{L}^{-1}$ polyol (erythritol or D-threitol). Finally, all absorbance spectra were plotted as the ratio $R / R_{0}$, where $R_{0}$ is the reference spectrum collected at $0.1 \mathrm{~V}$ and $R$ is the spectrum obtained as a function of the applied potential, including the spectrum recorded at $0.1 \mathrm{~V}$.

For product detection, we also performed electrolysis and HPLC analysis. However, the low amount of products detected did not permit to extract reliable conclusions.

Chemicals. All solutions were made with ultrapure water (18.2 $\mathrm{M} \Omega \mathrm{cm}^{-1}, 25^{\circ} \mathrm{C}$, Millipore), and chemicals were used without any prior purification. The chemicals used were perchloric acid (97\%, 99.999\% trace metals basis SigmaAldrich), D-threitol (99\%, Sigma-Aldrich), meso-erythritol ( $\geq 99 \%$, Sigma-Aldrich), D-erythronic acid $\gamma$-lactone (95.0\%, Sigma-Aldrich), L-(+)-erythulose ( $\geq 85 \%$, HPLC, SigmaAldrich), and deuterium oxide (99.9\% atom\% D, SigmaAldrich).

Computational Methods. Atomistic computer simulations were performed based on DFT using the VASP code (Vienna ab initio simulation package). ${ }^{22-24}$ The Kohn-Sham equations ${ }^{25,26}$ were solved using a periodic approach along the three directions with a plane-wave basis set. For the exchangecorrelation functional we used the generalized gradient approximation (GGA) with the parametrization of PerdewBurke-Ernzerhof (PBE). ${ }^{27}$ The effects of van der Waals interactions were taken into account by using Grimme's corrections to the PBE functional (PBE+D3). ${ }^{28,29}$ The PAW $\operatorname{method}^{30,31}$ was applied for the description of the core electrons.

The computational work focused on five double dehydrogenated adsorbed species derived from the erythritol which were bound to the three Pt single crystal basal planes (Figure 2 ). The intermediate doubly dehydrogenated at the $\mathrm{C} 1$ is
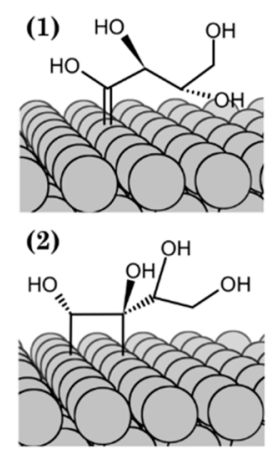

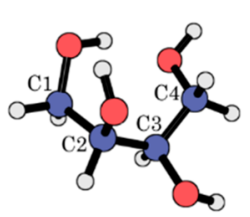

(3)
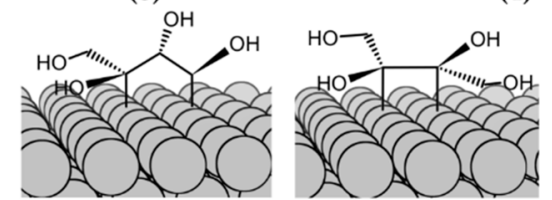

Figure 2. Overview of the five erythritol derived structures adsorbed on the $\mathrm{Pt}(100)$ surface and the numbering of the carbon atoms in the erythritol molecule.

named intermediate 1 ; the others were dehydrogenated in two different carbons, on $\mathrm{C} 1$ and $\mathrm{C} 2, \mathrm{C} 1$ and $\mathrm{C} 3, \mathrm{C} 2$ and $\mathrm{C} 3$, and, finally, $\mathrm{C} 1$ and $\mathrm{C} 4$, and named intermediates $2,3,4$, and 5 , respectively.

The calculations include the free platinum surfaces, the adsorption systems and the isolated molecules of erythritol and $\mathrm{H}_{2}$. The molecule was constructed in a nonsymmetric box of $20 \times 21 \times 19 \AA$. From the equilibrium lattice constant of 3.967 $\AA$ found for the Pt bulk (deviation of $1.2 \%$ from experimental 
measure $^{32}$ ), we created slab models for the (100), (111), and (110) Pt surfaces, with $4 \times 5,4 \times 4$, and $3 \times 5$ cells and 6, 5, and 5 atomic layers, respectively. The bottom two layers were kept fixed during geometry optimizations and a vacuum distance of $20 \AA$ was set to guarantee a negligible interaction between slab surfaces.

During the simulations, the orientation of the hydroxyl groups proved to be important. Therefore, we explored several different structures in order to obtain the most favorable ones. For the optimization we employed a plane-wave cutoff energy of $450 \mathrm{eV}$ and a $3 \times 3 \times 1$ k-points sampling, generated with the Monkhorst-Pack method. The convergence criteria were $0.01 \mathrm{eV} / \AA$ for the forces and $10^{-6} \mathrm{eV}$ for the electronic energy. The static calculations were performed with a $6 \times 6 \times 1 \mathrm{k}$ points mesh also generated using the Monkhorst-Pack method.

The energy trends of the intermediates on the three platinum surfaces was studied from the adsorption energies $\left(\Delta E_{\text {ads }}\right)$, calculated as follows:

$$
\Delta E_{\mathrm{ads}}=E_{\mathrm{Pt}-\text { surface }+ \text { intermediate }}-\left(E_{\mathrm{Pt}-\text { surface }}+E_{\text {Erythritol }}-E_{\mathrm{H}_{2}}\right)
$$

where $E_{\mathrm{Pt} \text {-surface+intermediate }}$ presents the energy of the adsorbatesubstrate system, $E_{\mathrm{Pt} \text {-surface }}$ represents the total energy of the $\mathrm{Pt}$ surface, $E_{\text {Erythritol }}$ represents the total energy of the free erythritol molecule, and $E_{\mathrm{H}_{2}}$ represents the total energy of free $\mathrm{H}_{2}$.

The free energies of adsorption $\left(\Delta G_{\text {ads }}\right)$ were obtained by adding vibrational zero-point energy $\left(\Delta E_{\mathrm{ZPE}}\right)$ and vibrational entropy corrections $(\Delta S)$ to the adsorption energies (eq 2 ). In order to calculate the free energies of adsorption, the most favorable structures were selected and the calculation of their vibrational frequencies were performed using density functional perturbation theory methodology (DFPT). ${ }^{33,34}$

$$
\Delta G_{\mathrm{ads}}=\Delta E_{\mathrm{ads}}+\Delta E_{\mathrm{ZPE}}-T \Delta S
$$

During the vibrational calculations, almost all surface atoms were kept frozen (the free energy variation of the platinum atoms was disregarded), except those involved in bonds, whereas the adsorbates were allowed to vibrate. The same was done for the free erythritol molecule and for $\mathrm{H}_{2}$. The zeropoint energy term was obtained through half of the sum of the vibrational frequencies multiplied by the Planck constant while the entropy change was computed from statistical mechanics ${ }^{35}$ considering the vibrational contribution but neglecting the translation contribution. This apparently strong approximation is acceptable when considering that all intermediates in gas phase should have similar translation entropy values, which must decrease to negligible values upon adsorption. Consequently, the translation entropy change has a similar contribution in all intermediates, and it is expected that it will not modify the trends reported here.

\section{RESULTS}

Electrochemical and Spectroscopic Results. Figure 3 shows the cyclic voltammetry of the electrooxidation of erythritol and threitol. Both molecules show similar voltammetric features which resemble the results obtained with glycerol, ${ }^{19,36}$ i.e., the onset potential is higher for $\mathrm{Pt}(100)$ than for $\mathrm{Pt}(111)$ and $\mathrm{Pt}(110)$. $\mathrm{Pt}(100)$ shows a sharper current peak and $\mathrm{Pt}(110)$ shows the lowest peak current.
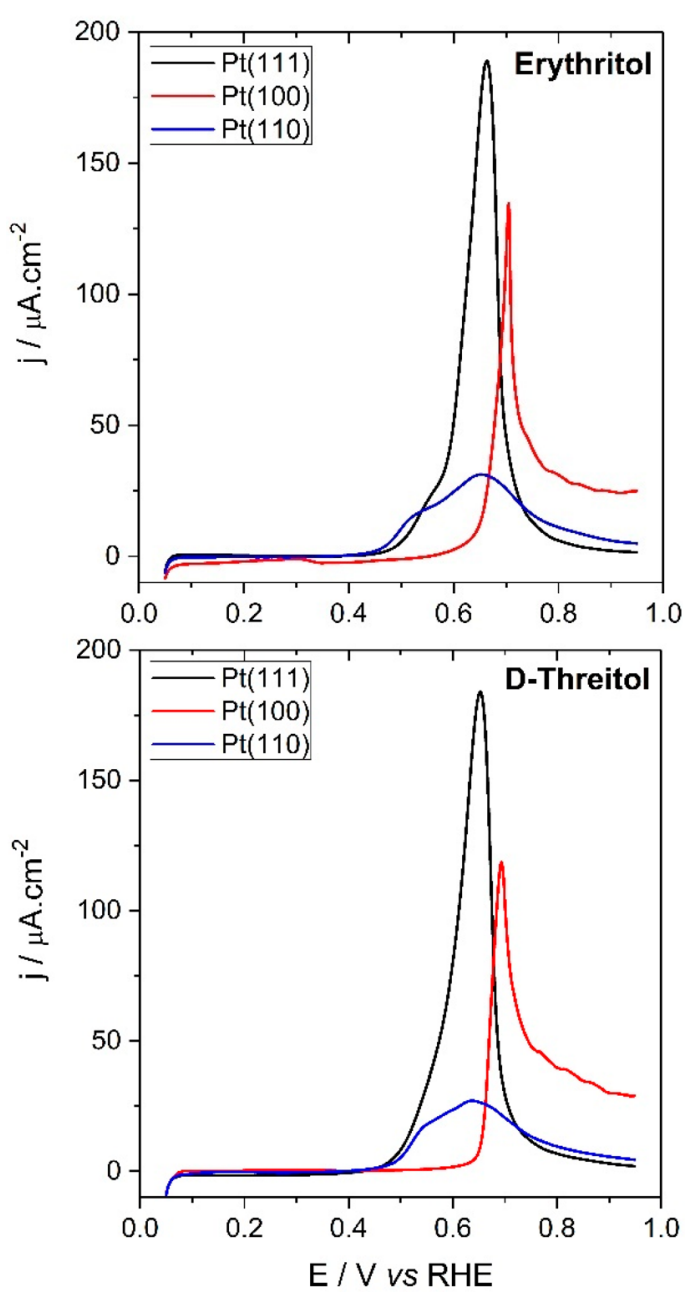

Figure 3. Positive-going sweep of the 1st cycle of the voltammetric response for the erythritol and $\mathrm{D}$-threitol oxidation in $0.1 \mathrm{~mol} \mathrm{~L}^{-1}$ $\mathrm{HClO}_{4}+5 \mathrm{mmol} \mathrm{L}-1$ polyol on $\mathrm{Pt}(111)$ and $\mathrm{Pt}(100)$. Sweep rate of 1 $\mathrm{mV} \mathrm{s}^{-1}$.

As in this work we are mainly interested in studying the selectivity of erythritol and threitol oxidation without $\mathrm{C}-\mathrm{C}$ bond breaking, we performed FTIR experiments in $\mathrm{D}_{2} \mathrm{O}$, as this solvent (compared to water) does not present bands in the region $1400-2000 \mathrm{~cm}^{-1}$, and therefore, the region of the stretching due to carbonyl containing compounds is easier analyzed than in water.

Figure 4 shows FTIR spectra obtained during the positivegoing sweep for the oxidation of erythritol on the threeplatinum single-crystal electrodes. The spectra show three main bands: at $1780 \mathrm{~cm}^{-1}$ (belonging to erythronic acid), at $1730 \mathrm{~cm}^{-1}$ (due to the formation of erythrulose), and a feature at $1100 \mathrm{~cm}^{-1}$ due to the entrance of $\mathrm{ClO}_{4}^{-}$anions in the thin layer. Figure S1 in the Supporting Information shows the transmission spectra for the dissolved reactants and products.

Figure 4 shows the impact of the Pt surface on the selectivity of the oxidation of the primary and secondary carbon of the $\mathrm{C}_{4}$ polyols. On $\mathrm{Pt}(111)$, we observe the bands corresponding to both erythrulose and to erythronic acid (see also Figure S2). On $\mathrm{Pt}(100)$ the bands corresponding to the oxidation products appear at higher potentials, in concordance with the electrochemical results. We observe again the production of erythrulose and erythronic acid, but in this case the relative intensity of the bands is inverted, with more primary oxidation 

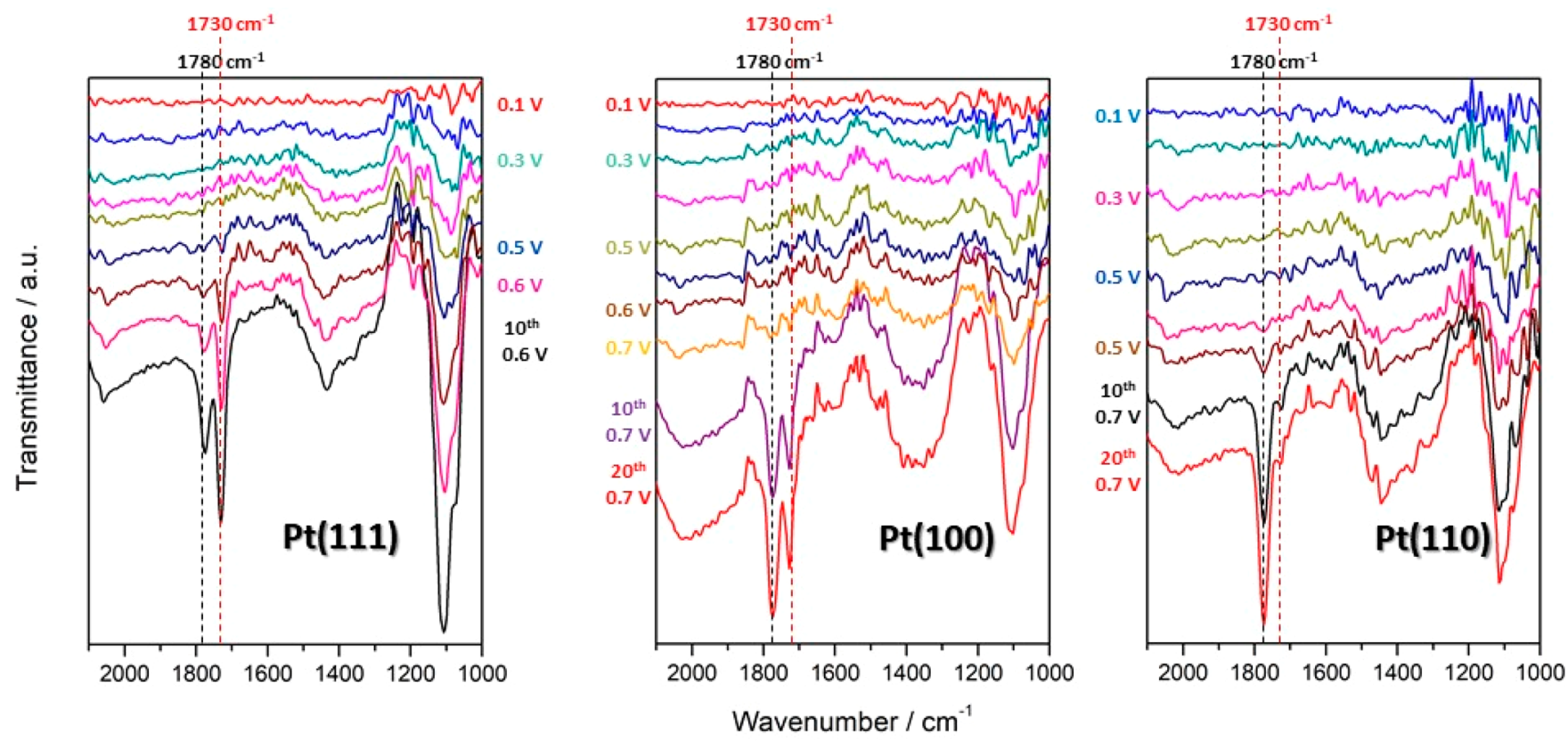

Figure 4. FTIR spectra taken at different electrode potentials (vs RHE) for the EOP in $0.1 \mathrm{~mol} \cdot \mathrm{L}^{-1} \mathrm{HClO}_{4}+5 \mathrm{mmol} \mathrm{L}{ }^{-1}$ erythritol on $\mathrm{Pt}(111$ ), $\mathrm{Pt}(100)$ and $\mathrm{Pt}(110)$. The potential was scanned up to $0,6 \mathrm{~V}$ for $\mathrm{Pt}(111)$ and $0,7 \mathrm{~V}$ for $\mathrm{Pt}(100)$ and $\mathrm{Pt}(110)$ and was held at these values to obtain 10 consecutive spectra for $\mathrm{Pt}(111)$ and 20 consecutive spectra for $\mathrm{Pt}(100)$ and $\mathrm{Pt}(110)$, to maximize the signal of the products obtained at those potentials. Figure S4-S6 show similar experiments but holding the potentials at other values.

product (see also Figure S3). Finally, Pt(110) oxidizes selectively the primary carbon (see also Figure S4). Experiments in Figures S2-S4 in the Supporting Information are the same as in Figure 4, but also spectra at other potentials were taken. These results permit us to conclude that the relative quantities of acid and ketone produced do not depend on the electrode potential (at least in the potential domain where we performed this study).

Figures S6 and S7 in the Supporting Information show the spectra obtained during the electrooxidation of erythritol and threitol on the three surfaces in nondeuterated water. All the spectra show an intense band at $2343 \mathrm{~cm}^{-1}$ due to the complete oxidation of the polyol to $\mathrm{CO}_{2}$, bands related to the presence of on top and bridge-bonded $\mathrm{CO}$, and a band at 1780 $\mathrm{cm}^{-1}$ due to the production of the carboxylic acid. More details can be found in the Supporting Information. These results show that there is a pathway that produces $\mathrm{CO}_{2}$, either through a previous formation of $\mathrm{CO}$ or through the oxidation of formic acid, as in the case of $\mathrm{GlOH}$ oxidation. ${ }^{11}$ These results are similar to those found with many other small organic molecules. Another important result is that in concordance with the electrochemical results in Figure 3, the FTIR spectra were very similar for erythritol and threitol (Figures S5 and S6).

Computational Experiments (DFT). Figure 5 shows the most stable configurations for the adsorbates of erythritol on the three Pt basal planes and the corresponding adsorption energies $\left(\Delta E_{\mathrm{ads}}\right)$ are plotted in Figure 6. Since the $\mathrm{C}_{4}$ polyol has more degrees of freedom than $\mathrm{GlOH}$ (studied in ref 19), many more configurations were studied in this work (Figure S7). We have not calculated activation barriers for adsorption as this would require very severe approximations. Our aim is a qualitative comparison, for which knowing the stability of intermediates is typically sufficient. ${ }^{37}$ Figure $S 8$ shows $\Delta E_{\text {ads }}$ and $\Delta G_{\text {ads }}$ using the PBE functional. The results show that both $\Delta E_{\mathrm{ZPE}}$ and $T \Delta S$ do not change the relative energies of the intermediates.

There is a clear trend for all the intermediates. The more open the surface is (i.e., surface atoms with lower coordination number), the stronger the adsorption of the intermediates is. This trend is common ${ }^{38}$ and has been observed by other researchers in similar systems. ${ }^{15,39,40}$ It is noteworthy in Figure 5 that most configurations tend to maximize the OH-surface interactions, allowing the carbon chain to adopt a configuration almost parallel to the platinum surface. As a result, Figure 6 shows that intermediate 3 is the most stable for all three surfaces. Besides, its energy difference with respect to the others intermediates show the trend $\operatorname{Pt}(110)>\operatorname{Pt}(100)>$ $\mathrm{Pt}(111)$. Intermediate 5 is the least stable for all surfaces and intermediates 1 and 2 have rather similar energies. An important difference arises when analyzing intermediate 4 . While it is relatively unstable in $\mathrm{Pt}(110)$ and $\mathrm{Pt}(100)$, it is the second most stable intermediate in $\mathrm{Pt}(111)$, due to a relatively higher stabilization by van der Waals interaction (compare Figure S8 and Figure 6).

\section{DISCUSSION}

The electrochemical and FTIR results show very similar responses for erythritol and threitol. Therefore, we conclude that the EOP is not sensitive to the spatial orientation of the $-\mathrm{OH}$ in the secondary carbon. This insensitivity to the orientation of the $\mathrm{OH}$ groups is in contrast with previous work, ${ }^{7}$ which may be due to different sources of threitol, though this hypothesis would require further study.

FTIR shows that $\mathrm{Pt}(111)$ and $\mathrm{Pt}(100)$ produce the ketone and the acid, however the selectivity ratio ketone/acid is higher for $\mathrm{Pt}(111)$. These finding are in line with those published by Garcia et al. ${ }^{17}$ for GlOH. Besides, we extended the results to $\mathrm{Pt}(110)$ and found that this surface is completely selective to the oxidation of the primary carbon. 


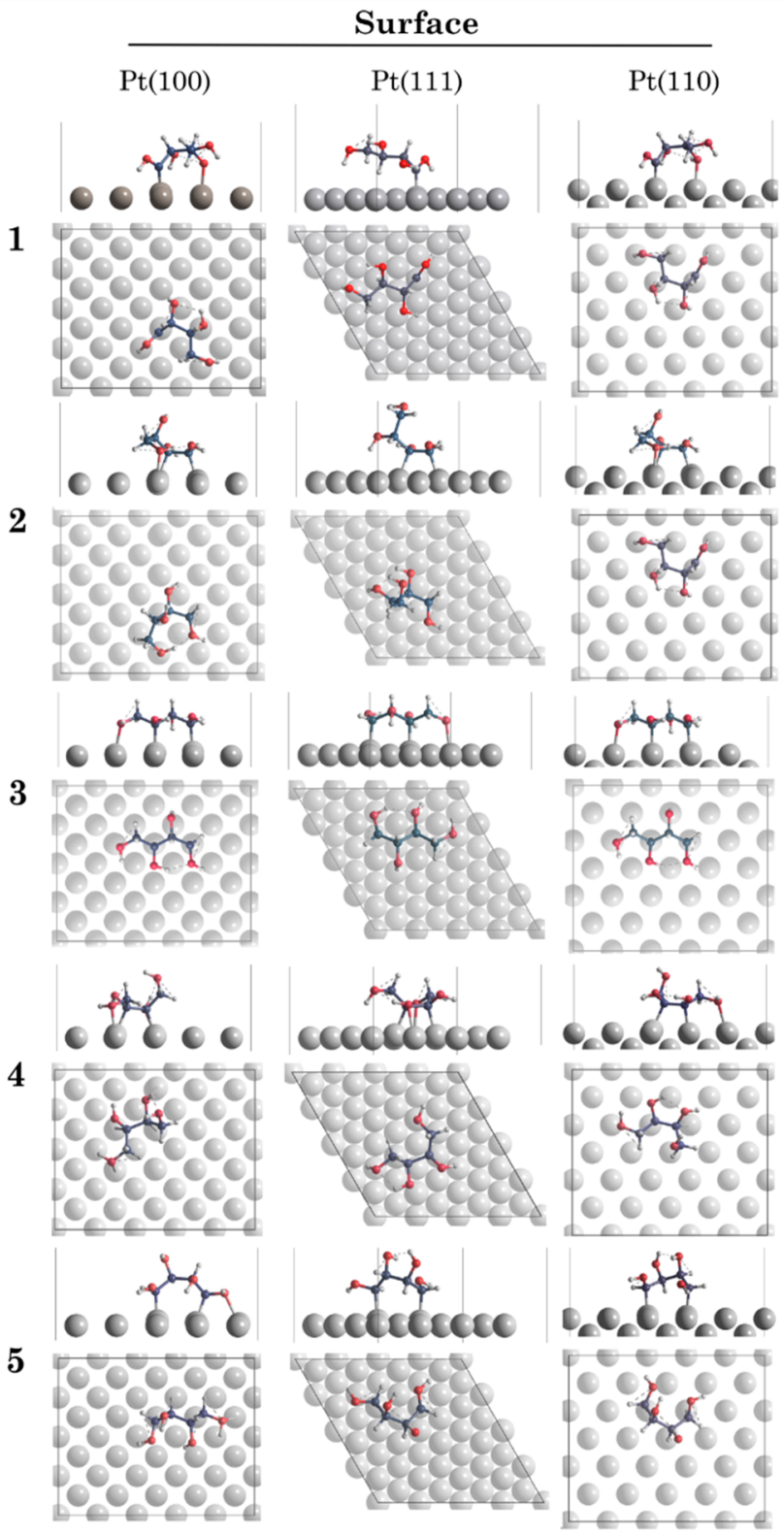

Figure 5. Top and side views of the most stable intermediates for $\mathrm{Pt}(100), \operatorname{Pt}(111)$, and $\mathrm{Pt}(110)$ surfaces.

To compare the computational results obtained with $\mathrm{GlOH}$ and erythritol, Figure 7 shows the structures of the intermediates proposed in ref 19, the equivalent structures for the erythritol and the intermediate 4.

Garcia et al. ${ }^{19}$ explained the higher ability for the oxidation of the secondary carbon of $\mathrm{GlOH}$ on $\mathrm{Pt}(111)$ by the more favorable adsorption energy of intermediate 2 (which is essentially an enediol) compared to intermediate 1 (considered the precursor of the aldehyde, which is easily oxidized to form the acid). The formation of the (adsorbed) enediol intermediate was considered crucial for the formation of the ketone (dihydroxyacetone in the case of glycerol oxidation), as the enediol is the key intermediate in the isomerization between the aldehyde and the ketone, and the ketone is the thermodynamically most stable isomer. ${ }^{41}$ In addition, for erythritol, we consider that the intermediate 4 could be also a precursor of the ketone.

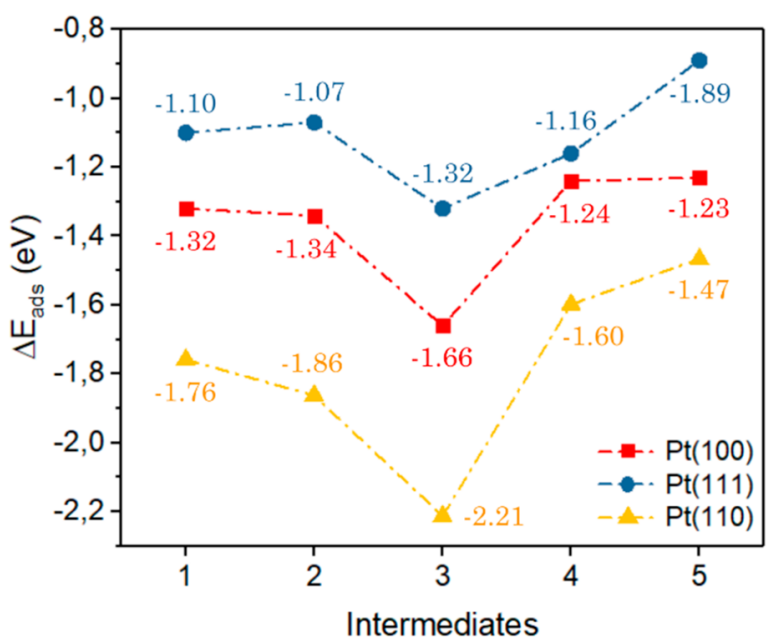

Figure 6. Adsorption energies for the five intermediates on $\operatorname{Pt}(100)$, $\operatorname{Pt}(111)$, and $\operatorname{Pt}(110)$.

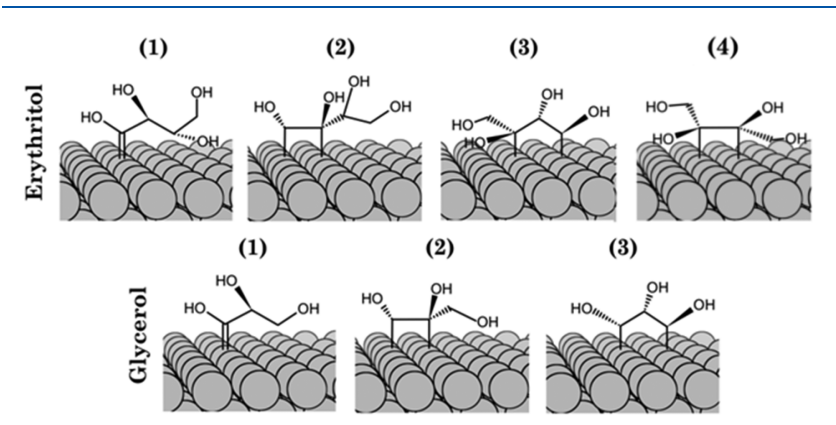

Figure 7. Side views of the double dehydrogenated intermediates 1, 2, and 3 of $\mathrm{GlOH}$ and 1, 2, 3, and 4 of erythritol.

As stated in ref 19 , intermediate 3 can be a precursor for a pathway toward the production of $\mathrm{C} 1$ and $\mathrm{C} 2$ molecules, but our results strongly suggest that it can be also oxidized to produce the acid. Its high stability explains the presence of this product on all surfaces, besides, the large difference in energy of intermediate 3 with the other intermediates explains the fact that $\mathrm{Pt}(110)$ selectively oxidizes the primary carbon.

Taking the stability of the (adsorbed) intermediates 2 and 4 compared to the stability of intermediate 3 as a measure for the relative selectivity to secondary alcohol oxidation, we see that the adsorption energies in Figure 6 can explain the experimental trend. Intermediates 2 and 4 are closer in energy to intermediate 3 on $\mathrm{Pt}(111)$ than on $\mathrm{Pt}(100)$, explaining the higher selectivity of $\mathrm{Pt}(111)$ toward the oxidation of the secondary carbon.

It is generally assumed that $\operatorname{Pt}(110)$ is the most representative surface for polycrystalline $\mathrm{Pt}\left(\mathrm{Pt}_{\mathrm{p}}\right.$; among the Pt basal planes). Consequently, this surface has shown a rather similar behavior to $\mathrm{Pt}_{\mathrm{p}}$ for the electrooxidation of $\mathrm{GlOH}^{42,43}$ Besides, it has been observed that several polyols (including $\mathrm{GlOH}$ and erythritol) are preferentially oxidized at their primary carbon on $\mathrm{Pt}_{\mathrm{p}}{ }^{7,44}$ Extending this to other polyols, we expect that $\mathrm{Pt}_{\mathrm{p}}$ will oxidize them to their corresponding carboxylic acid. Secondary alcohol oxidation requires the presence of (111) terrace sites, or the addition of promotors, which favorably interact with enediol intermediate. ${ }^{7,9,41,45}$ 


\section{CONCLUSION}

Through electrochemical, spectroelectrochemical, and computational experiments, we have studied the oxidation of $\mathrm{C}_{4}$ polyols on the Pt three basal planes.

The (spectro)electrochemical results showed that erythritol and threitol behave similarly, permitting us to conclude that the relative orientation of the $\mathrm{OH}$ groups do not play a role in the oxidation of these molecules.

Regarding the selectivity of the oxidation to the formation of the products without $\mathrm{C}-\mathrm{C}$ bond breaking, we found that the more open the surface is, the higher the relative oxidation of the primary carbon. By comparing our results with those previously published with other polyols, we suggest that these selectivity patterns are more general and can be extended to longer polyols.

The DFT calculations suggested that the trends in selectivity are governed by the relative stability of the doubly dehydrogenated intermediates. Only the adsorbed intermediate with enediol character, i.e., binding to the surface with neighboring carbons can give rise to the formation the ketone. We showed that the intermediates bound through the two secondary carbons have the relatively highest stability on $\mathrm{Pt}(111)$, explaining the relatively high production of the ketone on this surface. The most stable intermediate on all the surfaces binds through the primary and tertiary carbon, and we expect this intermediate to be a precursor for the formation of the acid.

\section{ASSOCIATED CONTENT}

\section{s) Supporting Information}

The Supporting Information is available free of charge at https://pubs.acs.org/doi/10.1021/acs.jpcc.0c05017.

FTIR spectra of products and reactants. FTIR in situ experiments of the electrooxidation of erythritol in $\mathrm{D}_{2} \mathrm{O}$ (complementing the results in Figure 4) and of erythritol and threitol in $\mathrm{H}_{2} \mathrm{O}$; structures of less stable intermediates than those presented in Figure 5 . Comparison between the adsorption energies and free adsorption energies for intermediates using the PBE parametrization. (PDF)

\section{AUTHOR INFORMATION}

\section{Corresponding Author}

Pablo S. Fernández - Chemistry Institute, State University of Campinas, 13083-970 Campinas, SP, Brazil; Center for Innovation on New Energies, University of Campinas, CEP 13083-841 Campinas, SP, Brazil; ○ orcid.org/0000-00025068-0556; Email: pablosf@unicamp.br

\section{Authors}

Gabriela Soffiati - Chemistry Institute, State University of Campinas, 13083-970 Campinas, SP, Brazil

José L. Bott-Neto - Chemistry Institute, State University of Campinas, 13083-970 Campinas, SP, Brazil; Center for Innovation on New Energies, University of Campinas, CEP 13083-841 Campinas, SP, Brazil; 이이이.org/0000-00031806-3280

Victor Y. Yukuhiro - Chemistry Institute, State University of Campinas, 13083-970 Campinas, SP, Brazil; Center for Innovation on New Energies, University of Campinas, CEP 13083-841 Campinas, SP, Brazil
Cléo T. G. V. M. T. Pires - Chemistry Institute, State University of Campinas, 13083-970 Campinas, SP, Brazil; () orcid.org/0000-0001-8330-2642

Carlos C. Lima - Chemistry Institute, State University of Campinas, 13083-970 Campinas, SP, Brazil

Cinthia R. Zanata - Institute of Chemistry, Universidade Federal do Mato Grosso do Sul, CEP 79070-900 Campo Grande, MS, Brazil

Yuvraj Y. Birdja - Leiden Institute of Chemistry, Leiden University, 2300 Leiden, The Netherlands; (1) orcid.org/00000002-7405-0022

Marc T. M. Koper - Leiden Institute of Chemistry, Leiden University, 2300 Leiden, The Netherlands; 이이.org/00000001-6777-4594

Miguel A. San-Miguel - Chemistry Institute, State University of Campinas, 13083-970 Campinas, SP, Brazil; 이이.org/ 0000-0002-6650-7432

Complete contact information is available at:

https://pubs.acs.org/10.1021/acs.jpcc.0c05017

\section{Notes}

The authors declare no competing financial interest.

\section{ACKNOWLEDGMENTS}

Financial support from the Brazilian agencies: P.S.F. and M.S.M. thank FAPESP (Grants 2018/20952-0, 2019/07449-0, 2013/07296-2, and 2016/23891-6). P.S.F. thanks Shell and the strategic importance of the support given by ANP (Brazil's National Oil, Natural Gas and Biofuels Agency) through the R\&D levy regulation. This work used computational resources of the "Centro Nacional de Processamento de Alto Desempenho em São Paulo" (CENAPAD-SP), "Centro de Computação John David Rogers” (CCJDR-UNICAMP), and the CENAPAD-RJ (SDumont).

\section{REFERENCES}

(1) Shell Global Sky scenariolShell Global; https://www.shell.com/ energy-and-innovation/the-energy-future/scenarios/shell-scenariosky.html (accessed Jan 27, 2020).

(2) Ptasinski, K. J. Biomass-Based Fuel Cell Systems. Efficiency of Biomass Energy; John Wiley \& Sons, Inc.: Hoboken, NJ, 2016; pp 633-672.

(3) Li, Y.; Liu, W.; Zhang, Z.; Du, X.; Yu, L.; Deng, Y. A SelfPowered Electrolytic Process for Glucose to Hydrogen Conversion. Commun. Chem. 2019, 2 (1), 67.

(4) Huang, W.-D.; Zhang, Y.-H. P. Energy Efficiency Analysis: Biomass-to-Wheel Efficiency Related with Biofuels Production, Fuel Distribution, and Powertrain Systems. PLoS One 2011, 6 (7), No. e22113.

(5) Oncescu, V.; Erickson, D. High Volumetric Power Density, NonEnzymatic, Glucose Fuel Cells. Sci. Rep. 2013, 3 (1), 1226.

(6) Holade, Y.; Tuleushova, N.; Tingry, S.; Servat, K.; Napporn, T. W.; Guesmi, H.; Cornu, D.; Kokoh, K. B. Recent Advances in the Electrooxidation of Biomass-Based Organic Molecules for Energy, Chemicals and Hydrogen Production. Catal. Sci. Technol. 2020, 10 (10), 3071-3112.

(7) Kwon, Y.; de Jong, E.; van der Waal, J. K.; Koper, M. T. M. Selective Electrocatalytic Oxidation of Sorbitol to Fructose and Sorbose. ChemSusChem 2015, 8 (6), 970-973.

(8) Kwon, Y.; Hersbach, T. J. P.; Koper, M. T. M. Electro-Oxidation of Glycerol on Platinum Modified by Adatoms: Activity and Selectivity Effects. Top. Catal. 2014, 57 (14-16), 1272-1276.

(9) Kwon, Y.; Birdja, Y.; Spanos, I.; Rodriguez, P.; Koper, M. T. M. Highly Selective Electro-Oxidation of Glycerol to Dihydroxyacetone 
on Platinum in the Presence of Bismuth. ACS Catal. 2012, 2 (5), 759-764.

(10) Melle, G. B.; Machado, E. G.; Mascaro, L. H.; Sitta, E. Eff Ect of Mass Transport on the Glycerol Electro-Oxidation. Electrochim. Acta 2019, 296, 972-979.

(11) Kwon, Y.; Schouten, K. J. P.; Koper, M. T. M. Mechanism of the Catalytic Oxidation of Glycerol on Polycrystalline Gold and Platinum Electrodes. ChemCatChem 2011, 3 (7), 1176-1185.

(12) Fernández, P. S.; Fernandes Gomes, J.; Angelucci, C. A.; Tereshchuk, P.; Martins, C. A.; Camara, G. A.; Martins, M. E.; Da Silva, J. L. F.; Tremiliosi-Filho, G. Establishing a Link between WellOrdered Pt(100) Surfaces and Real Systems: How Do Random Superficial Defects Influence the Electro-Oxidation of Glycerol? ACS Catal. 2015, 5 (7), 4227-4236.

(13) Fernández, P. S.; Martins, C. A.; Martins, M. E.; Camara, G. A. Electrooxidation of Glycerol on Platinum Nanoparticles: Deciphering How the Position of Each Carbon Affects the Oxidation Pathways. Electrochim. Acta 2013, 112, 686-691.

(14) Fernández, P. S.; Martins, M. E.; Martins, C. A.; Camara, G. A. The Electro-Oxidation of Isotopically Labeled Glycerol on Platinum: New Information on C-C Bond Cleavage and CO2 Production. Electrochem. Commun. 2012, 15 (1), 14-17.

(15) Fernández, P. S.; Tereshchuk, P.; Angelucci, C. A.; Gomes, J. F.; Garcia, A. C.; Martins, C. A.; Camara, G. A.; Martins, M. E.; Da Silva, J. L. F.; Tremiliosi-Filho, G. How Do Random Superficial Defects Influence the Electro-Oxidation of Glycerol on $\mathrm{Pt}(111)$ Surfaces? Phys. Chem. Chem. Phys. 2016, 18 (36), 25582-25591.

(16) de Souza, N. E.; Gomes, J. F.; Tremiliosi-Filho, G. Reactivity of 3-Carbon-Atom Chain Alcohols on Gold Electrode: A Comparison to Understand the Glycerol Electro-Oxidation. J. Electroanal. Chem. 2017, 800, 106-113.

(17) Gomes, J. F.; De Paula, F. B. C.; Gasparotto, L. H. S.; Tremiliosi-Filho, G. The Influence of the Pt Crystalline Surface Orientation on the Glycerol Electro-Oxidation in Acidic Media. Electrochim. Acta 2012, 76, 88-93.

(18) Gomes, J. F.; Martins, C. A.; Giz, M. J.; Tremiliosi-Filho, G.; Camara, G. A. Insights into the Adsorption and Electro-Oxidation of Glycerol: Self-Inhibition and Concentration Effects. J. Catal. 2013, 301, 154-161.

(19) Garcia, A. C.; Kolb, M. J.; van Nierop y Sanchez, C.; Vos, J.; Birdja, Y. Y.; Kwon, Y.; Tremiliosi-Filho, G.; Koper, M. T. M. Strong Impact of Platinum Surface Structure on Primary and Secondary Alcohol Oxidation during Electro-Oxidation of Glycerol. ACS Catal. 2016, 6 (7), 4491-4500.

(20) Clavilier, J.; Faure, R.; Guinet, G.; Durand, R. Preparation of Monocrystalline Pt Microelectrodes and Electrochemical Study of the Plane Surfaces Cut in the Direction of the $\{111\}$ and $\{110\}$ Planes. J. Electroanal. Chem. Interfacial Electrochem. 1980, 107 (1), 205-209.

(21) Clavilier, J.; Faure, R.; Guinet, G.; Durand, R. Preparation of Monocrystalline Pt Microelectrodes and Electrochemical Study of the Plane Surfaces Cut in the Direction of the $\{111\}$ and $\{110\}$ Planes. J. Electroanal. Chem. Interfacial Electrochem. 1980, 107 (1), 205-209.

(22) Kresse, G.; Furthmüller, J. Efficiency of Ab-Initio Total Energy Calculations for Metals and Semiconductors Using a Plane-Wave Basis Set. Comput. Mater. Sci. 1996, 6 (1), 15-50.

(23) Kresse, G.; Hafner, J. Ab Initio Molecular Dynamics for Liquid Metals. Phys. Rev. B: Condens. Matter Mater. Phys. 1993, 47 (1), 558561.

(24) Kresse, G.; Hafner, J. Ab Initio Molecular-Dynamics Simulation of the Liquid-Metal-Amorphous-Semiconductor Transition in Germanium. Phys. Rev. B: Condens. Matter Mater. Phys. 1994, 49 (20), 14251-14269.

(25) Hohenberg, P.; Kohn, W. Inhomogeneous Electron Gas. Phys. Rev. 1964, 136 (3B), B864-B871.

(26) Kohn, W.; Sham, L. J. Self-Consistent Equations Including Exchange and Correlation Effects. Phys. Rev. 1965, 140 (4A), A1133A1138.
(27) Perdew, J. P.; Burke, K.; Ernzerhof, M. Generalized Gradient Approximation Made Simple. Phys. Rev. Lett. 1996, 77 (18), 38653868.

(28) Grimme, S.; Antony, J.; Ehrlich, S.; Krieg, H. A Consistent and Accurate Ab Initio Parametrization of Density Functional Dispersion Correction (DFT-D) for the 94 Elements H-Pu. J. Chem. Phys. 2010, 132 (15), 154104.

(29) Grimme, S.; Ehrlich, S.; Goerigk, L. Effect of the Damping Function in Dispersion Corrected Density Functional Theory. J. Comput. Chem. 2011, 32 (7), 1456-1465.

(30) Blöchl, P. E. Projector Augmented-Wave Method. Phys. Rev. B: Condens. Matter Mater. Phys. 1994, 50 (24), 17953-17979.

(31) Kresse, G.; Joubert, D. From Ultrasoft Pseudopotentials to the Projector Augmented-Wave Method. Phys. Rev. B: Condens. Matter Mater. Phys. 1999, 59 (3), 1758-1775.

(32) Kittel, C. Introduction to Solid State Physics, 8th ed.; John Wiley \& Sons, Inc.: New York, 2004.

(33) Baroni, S.; de Gironcoli, S.; Dal Corso, A.; Giannozzi, P. Phonons and Related Crystal Properties from Density-Functional Perturbation Theory. Rev. Mod. Phys. 2001, 73 (2), 515-562.

(34) Karhánek, D.; Bučko, T.; Hafner, J. A Density-Functional Study of the Adsorption of Methane-Thiol on the (111) Surfaces of the NiGroup Metals: II. Vibrational Spectroscopy. J. Phys.: Condens. Matter 2010, 22 (26), 265006.

(35) Howalt, J. G.; Bligaard, T.; Rossmeisl, J.; Vegge, T. DFT Based Study of Transition Metal Nano-Clusters for Electrochemical NH3 Production. Phys. Chem. Chem. Phys. 2013, 15 (20), 7785-7795.

(36) Fernández, P. S.; Martins, C. A.; Angelucci, C. A.; Gomes, J. F.; Camara, G. A.; Martins, M. E.; Tremiliosi-Filho, G. Evidence for Independent Glycerol Electrooxidation Behavior on Different Ordered Domains of Polycrystalline Platinum. ChemElectroChem 2015, 2 (2), 263-268.

(37) Bligaard, T.; Nørskov, J. K.; Dahl, S.; Matthiesen, J.; Christensen, C. H.; Sehested, J. The Brønsted-Evans-Polanyi Relation and the Volcano Curve in Heterogeneous Catalysis. J. Catal. 2004, 224 (1), 206-217.

(38) Norskov, J. K.; Abild-Pedersen, F.; Studt, F.; Bligaard, T. Density Functional Theory in Surface Chemistry and Catalysis. Proc. Natl. Acad. Sci. U. S. A. 2011, 108 (3), 937-943.

(39) Tereshchuk, P.; Chaves, A. S.; Da Silva, J. L. F. Glycerol Adsorption on Platinum Surfaces: A Density Functional Theory Investigation with van Der Waals Corrections. J. Phys. Chem. C 2014, 118 (28), 15251-15259.

(40) Fernández, P. S.; Fernandes Gomes, J.; Angelucci, C. A.; Tereshchuk, P.; Martins, C. A.; Camara, G. A.; Martins, M. E.; Da Silva, J. L. F.; Tremiliosi-Filho, G. Establishing a Link between WellOrdered Pt(100) Surfaces and Real Systems: How Do Random Superficial Defects Influence the Electro-Oxidation of Glycerol? ACS Catal. 2015, 5 (7), 4227-4236.

(41) Garcia, A. C.; Birdja, Y. Y.; Tremiliosi-Filho, G.; Koper, M. T. M. Glycerol Electro-Oxidation on Bismuth-Modified Platinum Single Crystals. J. Catal. 2017, 346, 117-124.

(42) Fernández, P. S.; Martins, C. A.; Angelucci, C. A.; Gomes, J. F.; Camara, G. A.; Martins, M. E.; Tremiliosi-Filho, G. Evidence for Independent Glycerol Electrooxidation Behavior on Different Ordered Domains of Polycrystalline Platinum. ChemElectroChem 2015, 2 (2), 263-268.

(43) de Souza, M. B. C.; Yukuhiro, V. Y.; Vicente, R. A.; Vilela Menegaz Teixeira Pires, C. T. G.; Bott-Neto, J. L.; Fernández, P. S. $\mathrm{Pb}$ - and Bi-Modified Pt Electrodes toward Glycerol Electrooxidation in Alkaline Media. Activity, Selectivity, and the Importance of the Pt Atoms Arrangement. ACS Catal. 2020, 10 (3), 2131-2137.

(44) Cherqaoui, A.; Takky, D.; Kokoh, K. B.; Hahn, F.; Belgsir, E. M.; Léger, J. M.; Lamy, C. Electro-Oxidation of Meso-Erythritol on Platinum in Acid Medium: Analysis of the Reaction Products. J. Electroanal. Chem. 1999, 464 (1), 101-109.

(45) Kwon, Y.; Hersbach, T. J. P.; Koper, M. T. M. ElectroOxidation of Glycerol on Platinum Modified by Adatoms: Activity and Selectivity Effects. Top. Catal. 2014, 57 (14-16), 1272-1276. 